\title{
Immunohistochemical study of CD117 in various cutaneous melanocytic lesions
}

\author{
ANTONIA RADU ${ }^{1 *}$, CORNELIA BEJENARU $^{1 *}$, ION ŢOLEA $^{2}$, MINELA AIDA MARANDUCA $^{3 *}$, \\ DANIEL CONSTANTIN BRĂNIŞTEANU ${ }^{4}$, LUDOVIC EVERARD BEJENARU ${ }^{5}$, FLORIN DUMITRU PETRARIU ${ }^{6}$, \\ GABRIELA STOLERIU $^{7}$ and DACIANA ELENA BRĂNIŞTEANU ${ }^{8}$
}

${ }^{1}$ Department of Pharmaceutical Botany, ${ }^{2}$ Department of Dermatology, University of Medicine and Pharmacy of Craiova, Craiova 200349; Departments of ${ }^{3}$ Physiology, and ${ }^{4}$ Ophthalmology, 'Grigore T. Popa' University of Medicine and Pharmacy, Iaşi 700115; ${ }^{5}$ Department of Pharmacognosy and Phytotherapy, University of Medicine and Pharmacy of Craiova, Craiova 200349; ${ }^{6}$ Department of Preventive Medicine and Interdisciplinarity, 'Grigore T. Popa' University of Medicine and Pharmacy, Iaşi $700115 ;{ }^{7}$ Clinical Department, Faculty of Medicine and Pharmacy, 'Dunarea de Jos' University, Galati 800008; ${ }^{8}$ Department of Dermatology, 'Grigore T. Popa' University of Medicine and Pharmacy, Iaşi 700115, Romania

Received September 9, 2020; Accepted October 9, 2020

DOI: $10.3892 /$ etm.2020.9510

\begin{abstract}
The aim of the present study was to carried out a comparative immunohistochemical evaluation of CD117 (c-Kit), a biomarker that evaluates both tumor progression and prognosis, in different melanocytic lesions, to emphasize the significance of this biomarker in malignant melanoma (MM). The study was performed on 55 cases, represented by a control group, which included 5 cases of simple nevi and 5 cases of dysplastic nevi, as well as a study group consisting of 35 cases of primary MM and 10 metastases (one intestinal, 3 cutaneous - one satellite and two distant as well as 6 in the lymph nodes). The study group included 15 cases of superficial spreading melanoma (SSM), 10 cases of nodular melanoma (NM), 3 lentigo maligna melanoma (LMM), 3 cases of acral lentiginous melanoma (ALM) and 4 cases of amelanotic MM. CD117 was found to be massively involved in the process of tumorigenesis of cutaneous malignancies, being immunohistochemically undetectable in benign neural lesions, but densely expressed in dysplastic lesions and in situ
\end{abstract}

Correspondence to: Professor Daniel Constantin Brănişteanu, Department of Ophthalmology, 'Grigore T. Popa' University of Medicine and Pharmacy, 16 Universităţii Street, Iasi 700115, Romania

E-mail: dbranisteanu@yahoo.com

Professor Gabriela Stoleriu, Clinical Department, Faculty of Medicine and Pharmacy, 'Dunarea de Jos' University, 35 Alexandru Ioan Cuza Street, Galati 800008, Romania

E-mail: stoleriugabriela@yahoo.com

${ }^{*}$ Contributed equally

Key words: melanoma, CD117, immunohistochemistry, tumorigenesis, tyrosine kinase inhibitors melanoma areas. In invasive cutaneous MMs, CD117 expression tended to decrease with neoplasia progression proceding into the tumorigenic, vertical growth phase, being lower in the profound dermal component of tumors and in nodular MMs. To eliminate the epidermal barriers and gain a proliferative advantage to allow the transition to the vertical growth phase, it seems that MM should lose expression of c-Kit. Cutaneous metastases were found to express CD117 at a level comparable to their primary tumors, suggesting that other mechanisms interfere directly with the metastatic process and not loss of c-Kit expression by itself. CD117 overexpression in cutaneous melanocytic lesions correlates significantly with increased immunostaining intensity, suggesting that the immunohistochemical evaluation of CD117 may be a good method for screening patients, who could benefit from personalized therapy with tyrosine kinase inhibitors.

\section{Introduction}

Proto-oncogene CD117 encodes a trans-membrane tyrosine kinase receptor linked to the PDGF/CSF-1 receptor (c-fms) subfamily, platelet-derived growth factor (1). The c-Kit receptor is involved in the growth and development of mast cells and premature stromal cells or Cajal interstitial cells (2). Activation of Kit normally occurs when two adjacent receptors are fused together by a homodimer ligand. Subsequently, a series of events occur to activate cell signaling cascades, which are important in regulating proliferation, apoptosis, adhesion and differentiation in several cell types $(3,4)$. It plays an important role in the development of several cell types, including hematopoietic cells, germ cells and melanocytes (4-6).

Regarding malignant melanoma (MM) tumorigenesis, most tumors appear in the epidermis, in the melanocytes from the dermo-epidermal junction, being in situ (entirely epidermal) or invasive (extending from the epidermis into the dermis). Occasionally, invasive MMs are, however, localized entirely intradermally at the time of diagnosis. Invasive MM 
can be: non-tumorigenic (in the 'radial growth phase') or tumorigenic (in the 'vertical growth phase'). MM in situ and invasive non-tumorigenic MM can be divided into: Lentigo maligna, superficial spreading melanoma, acral lentiginous and lentigo on the mucosa.

Tumorigenic MM may appear on a pre-existing non-tumorigenic component of any of the above types, in which case it is appropriately named. However, tumorigenesis may also occur 'de novo', with no evidence of an in situ adjacent or microinvasive component at the time of detection, in which case it is called 'nodular MM' (7). However, most of the lesions probably originate through an intraepidermic nontumorigenic component that fails to develop or persist while the tumorigenic component evolves.

Important categories of tumorigenic MMs include desmoplastic MM and neurotropic MM. More rare types of MMs have been described, such as minimal deviation MM/MM with minus deviation, balloon cell MM, amelanotic MM, malignant blue nevus, congenital melanocytic nevus, clear cell sarcoma, melanocytic malignant schwannoma and approximately $5-10 \%$ of MM fall into 'unclassified' (NOS) or 'other' categories.

As a result, there are two major categories of MM, which are sequential stages or 'phases' of stepping tumor progression. In non-tumorigenic, radial or horizontal growth, neoplastic melanocytes are limited to the epidermis (melanoma in situ) or to the epidermis and papillary dermis, without the formation of an expansive tumor mass (MM microinvasive). This phase can be followed, after various time intervals, by the vertical growth phase. Also, dermal and/or epidermal structures of an associated nevus can be recognized in some MM.

Recent advances in molecular biology bring additional information that solves many issues related to MM tumorigenesis $(8,9)$. It appears that melanocytic stem cells, in addition to melanocytes, participate in the initiation and progression of cutaneous MM (10-12).

Basically, most skin MMs start with slow on-site growth and micro-invasive phase, and patients diagnosed at this stage have a high rate of healing. Despite a tendency for early clinical recognition of cutaneous $\mathrm{MM}$, at the time of diagnosis, most cutaneous MMs have already progressed to the next phase of growth characterized by rapid growth. In patients diagnosed at this stage, healing becomes uncertain and the prognosis depends on certain attributes of the neoplasm and the host (stroma and immunity). In general, the clinical progression of cutaneous $\mathrm{MM}$ is partly correlated with the expansion of its germ cell (13). Thus, the proportion of cells involved in the cell proliferation cycle will increase in cutaneous MM (14,15). In the present study, we analyzed CD117 (c-Kit), an immunohistochemical marker that evaluates both tumor progression and prognosis and which may be a therapeutic target in MM cases.

\section{Patients and methods}

Patients and tissue samples. The immunohistochemical study was performed on 55 cases (52\% female and $48 \%$ male, aged between 23 and 81 years with a mean age of 62.67) represented by a control group, which included 5 cases of simple nevi and 5 cases of nevi with dysplastic lesions, as well as a study group consisting of 35 cases of MM primary and 10 metastases (one intestinal, 3 cutaneous - one satellite and two distant as well as six in the lymph nodes). The study group included 15 cases of superficial spreading melanoma (SSM), 10 cases of nodular melanoma (NM), 3 lentigo maligna melanoma (LMM), 3 cases of acral lentiginous melanoma (ALM) and 4 cases of amelanotic MM. All biopsies were performed at The Clinical Emergency County Hospital Craiova, between January 2012 and December 2016.

The study was approved by the Universitary and Scientific Deontology and Ethics Committee of the University of Medicine and Pharmacy of Craiova (no. 78 from 27.03.2015), and informed consent was obtained from each patient.

Immunohistochemical methods. The immunohistochemical study method used to identify the epitopes of interest was one-time, polymer-specific, with high sensitivity, high specificity and high affinity. The characteristics of the antibody and the external controls used are shown in Table I.

From the paraffin blocks, $3-\mu \mathrm{m}$ series sections were made, which were inserted into the Leica BOND-MAX self-tester (Leica Biosystems), and the machining was carried out automatically according to the manufacturer's specifications. Note that the sections were incubated with the primary antibody for $1 \mathrm{~h}$ and a Bond Polymer Refine RED Detection System (Leica Biosystems) was used to detect the primary antibody, visualization of RED immunoreaction. Contrasting was performed in Mayer's hematoxylin solution.

Positive external controls were used (Table I) and appropriate negative external controls throughout the testing process. Negative external controls were tissue samples from the analyzed cases, to which the primary antibody was replaced with non-immune Ig serum from the same species as the primary antibody used. Mast cells were used as an internal positive control for CD117. Tumor cells showing cytoplasmic and/or membrane immunoreactivity for CD117 (c-Kit) were considered positive.

The percentage of positive cells was estimated for CD117 immunoassay and cases were classified in one of the following categories: 0 (negative cases, no positive cells), cases with under $10 \%$, between $10-50 \%$ and over $50 \%$ positive cells. In addition, the intensity of immunostaining was recorded semi-quantitatively: 0 (negative), +1 (weak), +2 (medium/moderate), +3 (strong).

Methods of statistical analysis. Average values and confidence intervals were used, as well as comparative tests (Chi-square) for consignments made using the SPSS 10 software (SPSS, Inc.). The Chi-square test was used to interpret incidence tables; the data were appreciated from the point of view of the dependence between the two classification factors, retaining only the results $>5 \%$, considered a sufficient materiality threshold. This test indicated whether there is a relationship (mutual influence) between two factors. The commands used in the software were Analyse, Descriptive Statistics and CrossTabs. Continuous numeric data was grouped by categories and plotted as standard \pm standard deviations using the Microsoft Excel package.

Statistical analysis was then performed using the SPSS package (SPSS, Inc.). For two categories of comparisons, 
Table I. Antibody used: clone, dilution, pretreatment, manufacturer and external control.

\begin{tabular}{lccccc}
\hline Antibody & Clone & Dilution & Pre-treatment & Manufacturer & External control \\
\hline CD117 & T595 & $1: 50$ & Solution citrate pH 6.0 x20 min in microwave & Leica Microsystems ${ }^{\mathrm{a}}$ & GIST \\
\hline
\end{tabular}

${ }^{\mathrm{a} C}$ atolog number (CD117-032-L-CE). GIST, gastrointestinal stromal tumors; min, minutes.

Table II. Distribution of cases according to the percentage of CD117-positive cells and the type of lesions.

\begin{tabular}{|c|c|c|c|c|c|}
\hline \multirow[b]{2}{*}{ Type of lesions $(\mathrm{N}=55)$} & \multirow[b]{2}{*}{ No. of cases } & \multicolumn{4}{|c|}{ IHC of CD117 (\% positive cells) } \\
\hline & & 0 (negative) & $<10 \%$ & $10-50 \%$ & $>50 \%$ \\
\hline Simple nevus & 5 & 5 & 0 & 0 & 0 \\
\hline Dysplastic nevus & 5 & 0 & 3 & 1 & 1 \\
\hline LMM & 3 & 0 & 0 & 0 & 3 \\
\hline SSM & 15 & 1 & 2 & 5 & 7 \\
\hline NM & 10 & 3 & 4 & 2 & 1 \\
\hline ALM & 3 & 0 & 0 & 1 & 2 \\
\hline Amelanotic MM & 4 & 1 & 1 & 1 & 1 \\
\hline Metastases & 10 & 3 & 2 & 4 & 1 \\
\hline
\end{tabular}

LMM, lentigo maligna melanoma; SSM, superficial spreading melanoma; NM, nodular melanoma; ALM, lentiginous melanoma; MM, malignant melanoma; IHC, immunohistochemistry.

Table III. Distribution of the cases according to percentage of CD117-positive cells and the immunostaining intensity.

\begin{tabular}{lcccc}
\hline & \multicolumn{4}{c}{ IHC of CD117 (\% positive cells) } \\
\cline { 2 - 5 } Intensity & 0 (negative) & $<10 \%$ & $10-50 \%$ & Over 50\% \\
\hline 0 (13 cases) & 13 & 0 & 0 & 0 \\
+1 (16 cases) & 0 & 7 & 7 & 2 \\
$+2(16$ cases) & 0 & 3 & 5 & 8 \\
+3 (10 cases) & 0 & 2 & 2 & 6 \\
\hline
\end{tabular}

IHC, immunohistochemistry.

the Student's-test comparison test was used. For more than two categories to be compared, a one-way ANOVA test with post-hoc analysis was used using the Tukey's test to evaluate the differences between the pairs of categories.

The quantification of the statistical results was as follows: i) $\mathrm{P}<0.05$, the difference is significant (S); ii) $\mathrm{P}<0.01$, the difference is highly significant (HS); iii) $\mathrm{P}<0.001$, the difference is very highly significant (VHS); iv) $\mathrm{P}>0.05$, the difference is not significant (NS).

Ethical principles. In the course of the study, the ethical principles underlying the Helsinki Declaration and the University Ethics Code on the good conduct of the research, along with the codes of practice established by the Code of Medical Deontology, were respected.

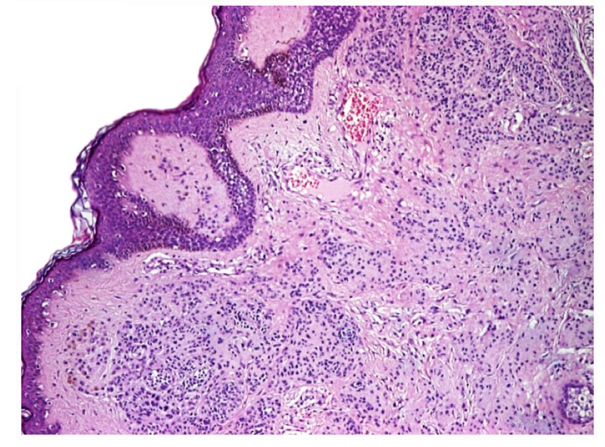

Figure 1. Light microscopy of a paraffin-embedded dermic nevus, stained with $\mathrm{H} \& \mathrm{E}, \mathrm{x} 40$ magnification. H\&E, hematoxylin and eosin.

\section{Results}

Of the total of 55 cases selected for the IHC study, the majority, $76.36 \%$ of cases (42 cases) showed positive immunostaining at CD117. The distribution of CD117 expression (as a percentage of marker cells and immunostaining intensity) of the melanocytic lesion studied is shown in Tables II and III.

Thus, the vivid nevi did not show immunostaining at CD117, all cases being negative for this marker (100\% negative) (Figs. 1 and 2), and the dysplastic nevi showed positive immunostaining in the areas of dysplasia (which are located superficially at the junction dermal-epidermal) in all cases (100\% positive) (Figs. 3-5). Dysplastic nevi (60\%) exhibited under $10 \%$ of CD117-positive cells, $20 \%$ of which were positive in $10-50 \%$ of tumor cells and $20 \%$ in over $50 \%$ of tumor cells, +2 and +3 (Tables II and III). 


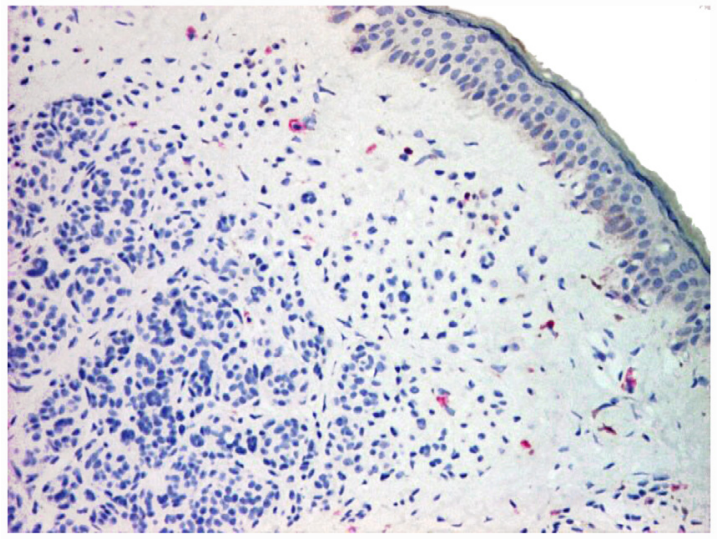

Figure 2. Light microscopy of a paraffin embedded dermic nevus, negative immunostaining for CD117; $x 40$ magnification.

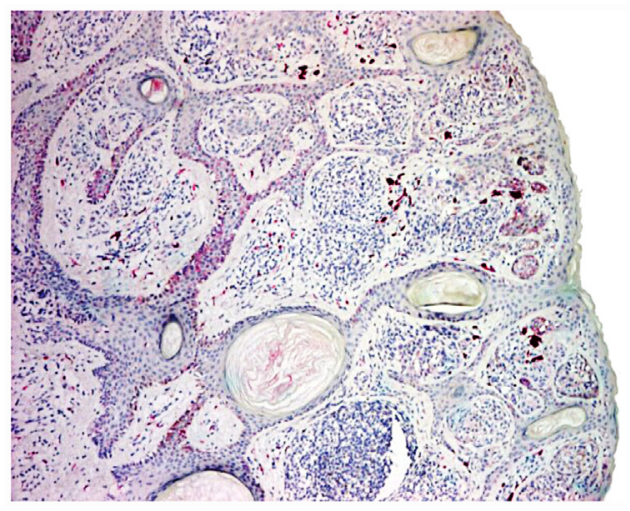

Figure 3. Light microscopy of a paraffin-embedded compound nevus with dysplasia outbreak, light positive immunostaining for CD117; x40 magnification.

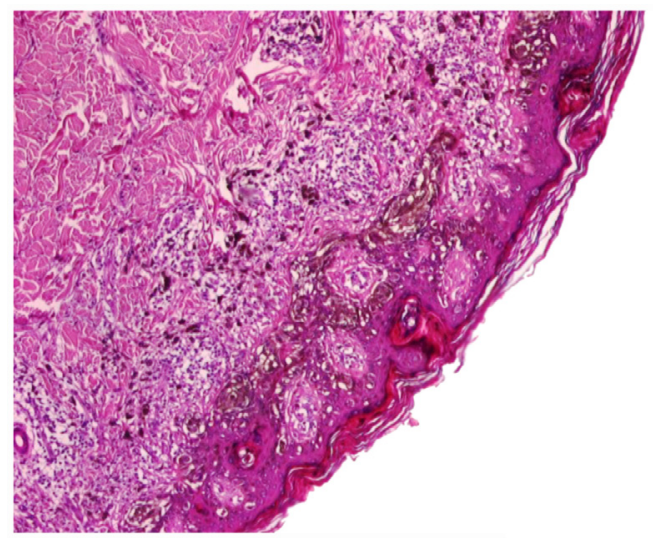

Figure 4. Light microscopy of a paraffin-embedded dysplastic nevus, stained with $\mathrm{H} \& \mathrm{E} ; \mathrm{x} 40$ magnification. H\&E, hematoxylin and eosin.

LMM showed positive immunostaining in all three cases ( $100 \%$ of positive cases), in over $50 \%$ of tumor cells in both malignant lentigo and melanoma areas (Figs. 6 and 7). The immunomarker intensity was +2 and +3 and was comparable in the lentigo and melanoma areas (Tables II and III).

SSM was negative in CD117 in one case (6.67\% negative), only 2 cases $(13.33 \%$ ) had immunostaining in below $10 \%$ of tumor cells, 5 cases $(33.33 \%)$ presenting $10-50 \%$ of the marked
A

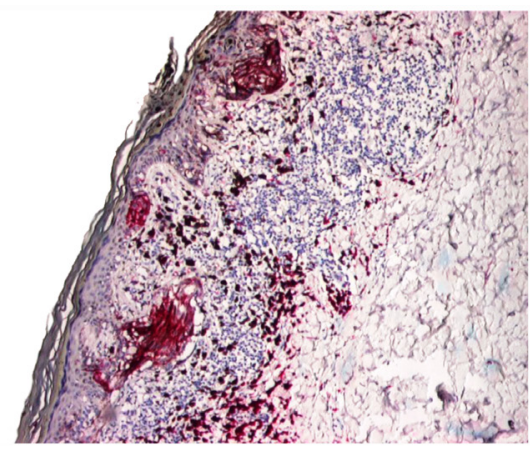

B

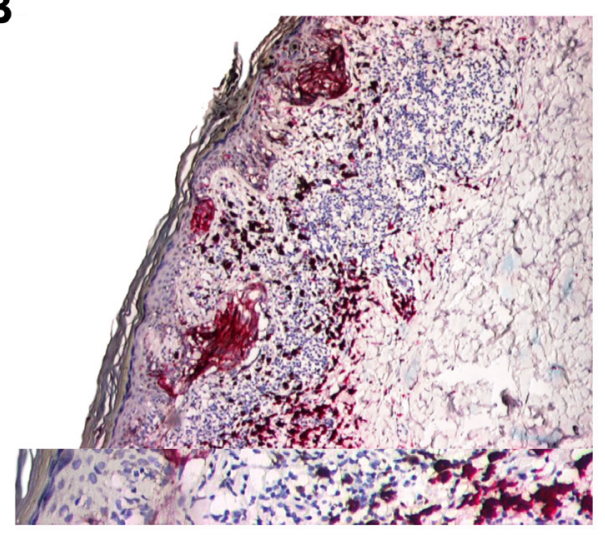

Figure 5. (A) Light microscopy of a paraffin embedded junctional dysplastic nevus syndrome, immune marked for CD117, x40. (B) Light microscopy of a paraffin embedded junctional dysplastic nevus syndrome, immune marked for CD117, x100.

A

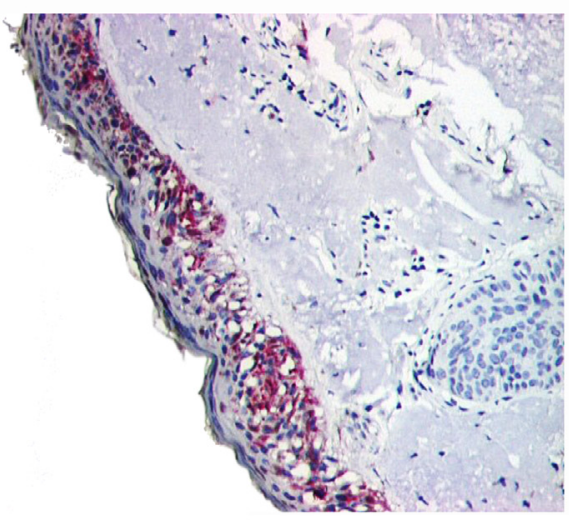

B

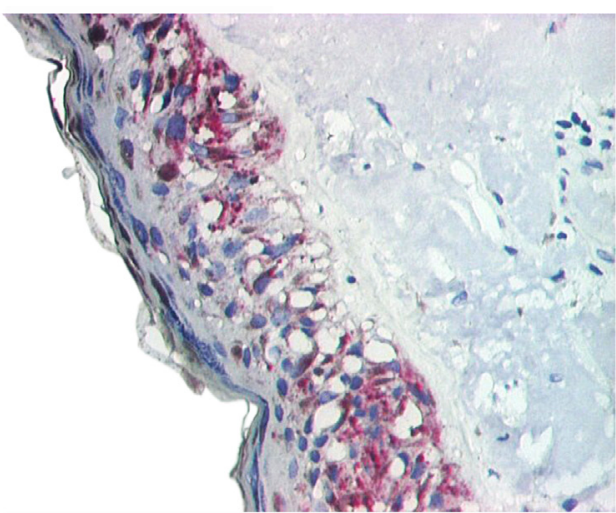

Figure 6. (A) Light microscopy of a paraffin-embedded LMM-malignant lentigo area, immunostaining for CD117; x100 magnification. (B) Light microscopy of a paraffin-embedded LMM-malignant lentigo area, immunostaining for CD117; x200 magnification. LMM, lentigo maligna melanoma. 


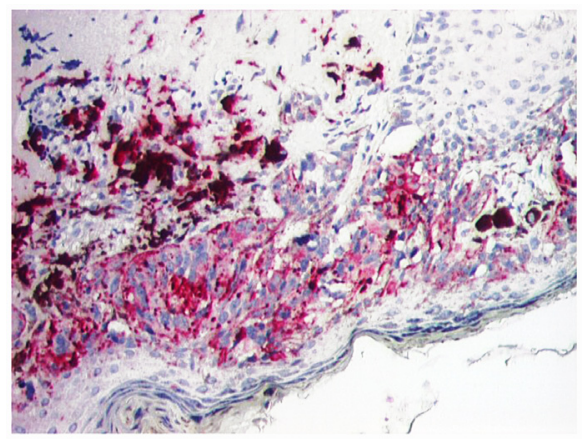

Figure 7. Light microscopy of a paraffin-embedded LMM-melanoma area, immunostaining for CD117; x100 magnification. LMM, lentigo maligna melanoma.

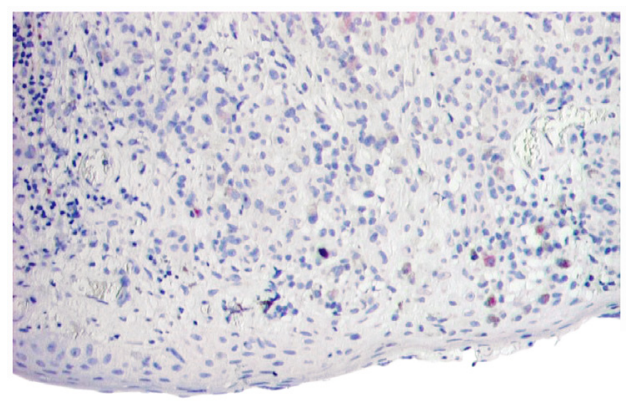

Figure 8. Light microscopy of a paraffin-embedded SSM, positive immunostaining for CD117-in isolated cells; x100 magnification. SSM, superficial spreading melanoma.
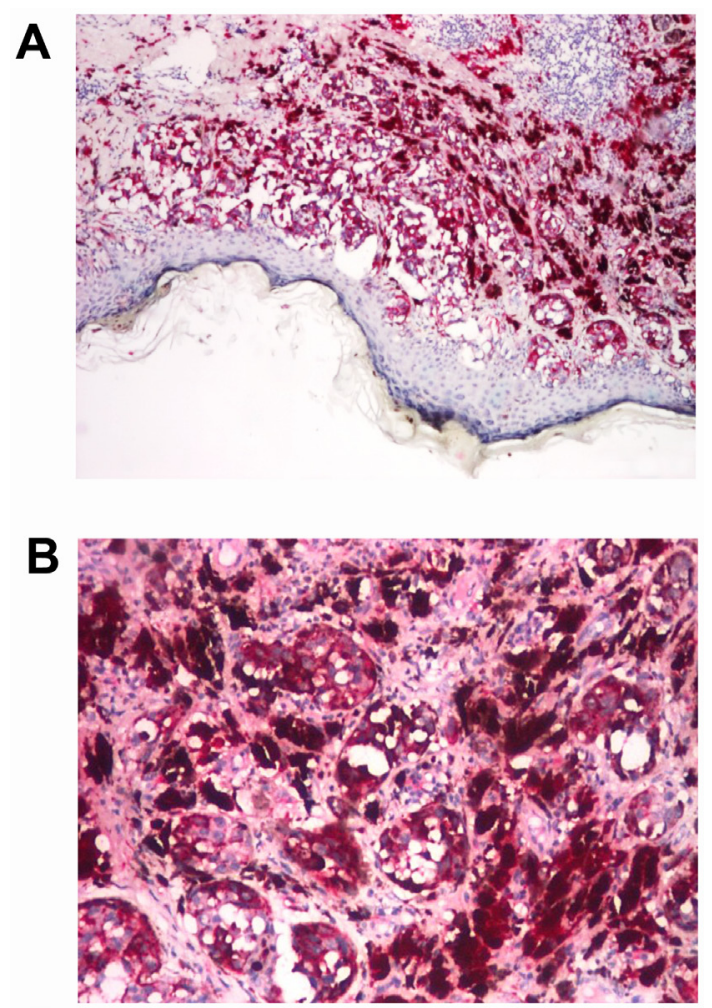

Figure 9. (A) Light microscopy of a paraffin-embedded SSM, strongly positive immunostaining for CD117, x40 magnification. (B) Light microscopy of a paraffin-embedded SSM, strongly positive immunostaining for CD117; x100 magnification. SSM, superficial spreading melanoma.

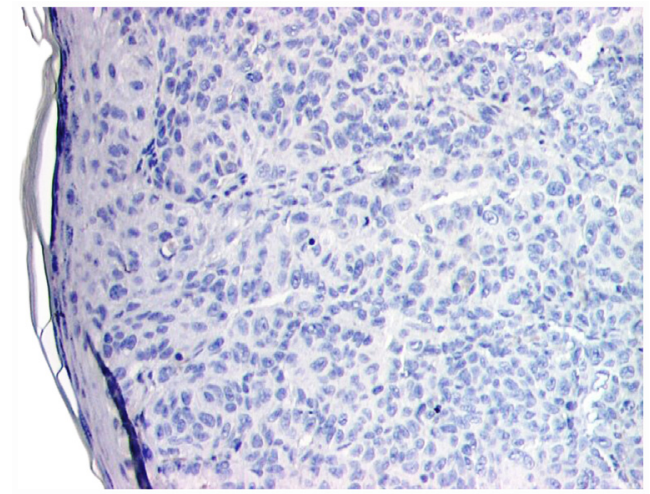

Figure 10. Light microscopy of a paraffin-embedded SSM, negative immunostaining for CD117; x100 magnification. SSM, superficial spreading melanoma.
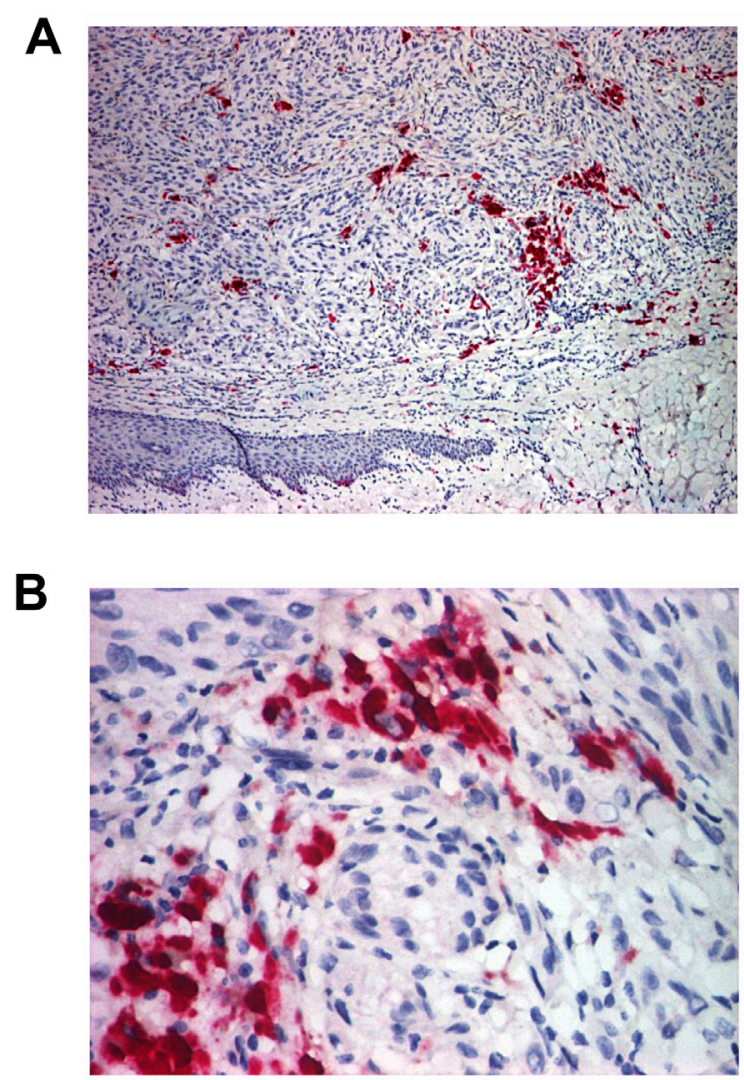

Figure 11. (A) Light microscopy of a paraffin-embedded NM, negative immunostaining for CD117; x40 magnification. (B) Light microscopy of a paraffin embedded NM, negative immunostaining for CD117; x100 magnification. NM, nodular melanoma.

cells and the remaining 7 cases (46.67\%) were being positive in over $50 \%$ of the tumor cells (Figs. 8-10). The immunomarker intensity was high, with scores of +2 and +3 , one case having a +1 score (Tables II and III). A feature of the immunostaining on CD117 in SSM was that, frequently, the intensity of immunostaining decreased to the depth of the tumors compared to the dermo-epidermal junction.

Regarding NM, we observed a relatively high number of negative cases, 3 cases (30\% negative), followed by 4 cases $(40 \%)$ with just under $10 \%$ positive cells, only 2 cases (20\%) positive between $10-50 \%$ of the tumor cells and only 


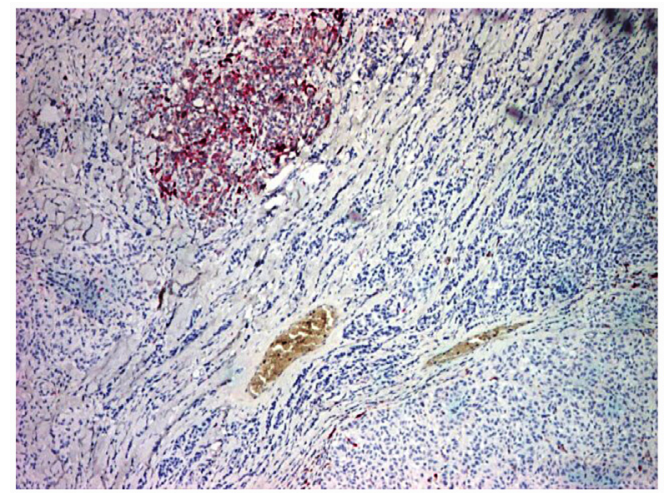

Figure 12. Light microscopy of a paraffin-embedded NM, positive immunostaining for CD117 only at the invasion front; $\mathrm{x} 40$ magnification. NM, nodular melanoma
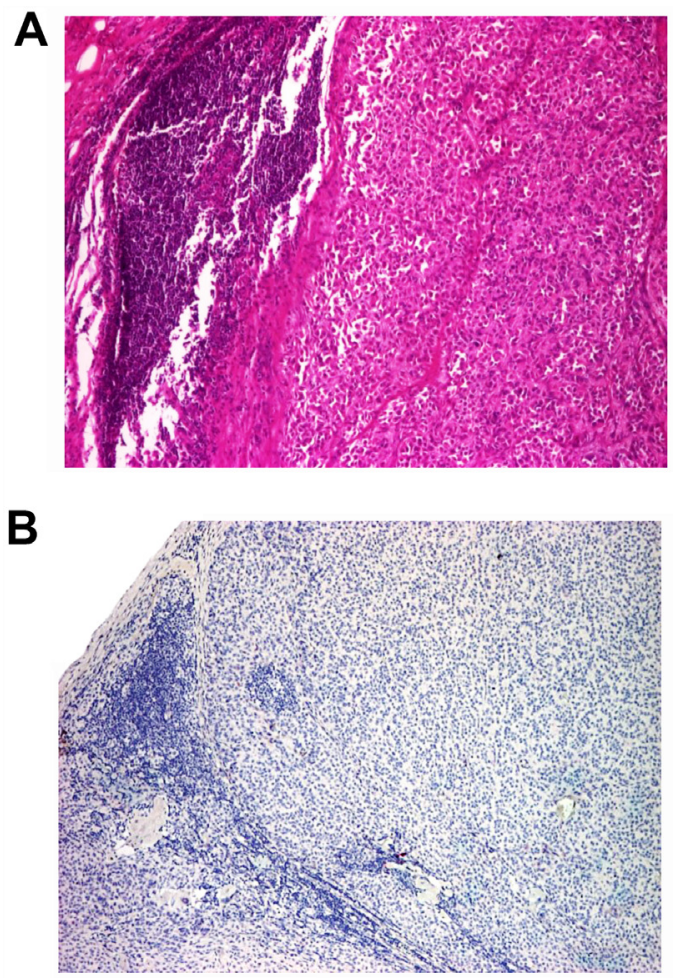

Figure 13. (A) Light microscopy of a paraffin-embedded MM metastasis in the lymph node, stained with $\mathrm{H} \& \mathrm{E}$; $\mathrm{x} 40$ magnification. (B) Light microscopy of a paraffin-embedded MM metastasis in the lymph node, negative immunostaining for CD117; x40 magnification. MM, malignant melanoma; H\&E, hematoxylin and eosin.

1 case $(10 \%)$ was positive in over $50 \%$ of the tumor cells (Figs. 11 and 12). The immunomarker intensity was generally mild and moderate, with scores of +1 and +2 , with only one case of high intensity +3 , but in under $10 \%$ of tumor cells (Tables II and III). One aspect noted in the CD117 marker in NM was that, in contrast to SSM, the immunostaining for CD117 was sometimes more intense in the depth of the tumors, namely in the tumor invasion front (in $40 \%$ of cases, the invasion front was the only immunostaining of CD117, but in under $20 \%$ of total tumor cells) (Fig. 12).

ALMs were positive in all three cases (100\% positive) with moderate and large (case 2 and 3, two cases); 1 case showing

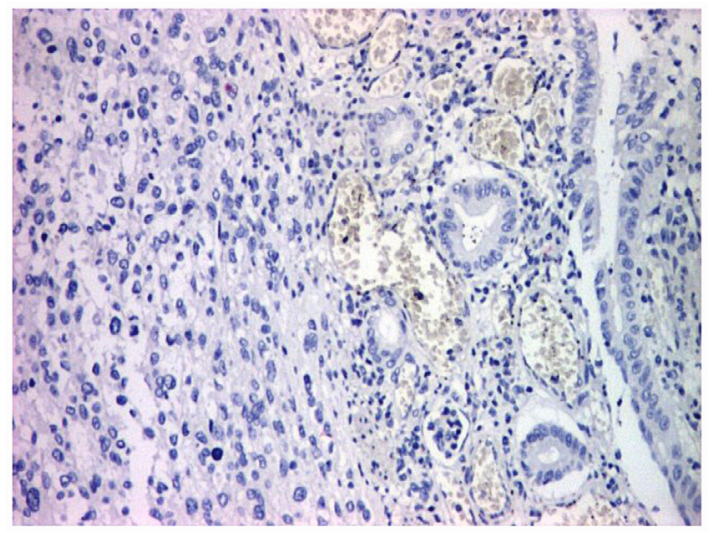

Figure 14. Light microscopy of a paraffin-embedded MM metastasis in the small intestine, negative immunostaining for CD117. MM, malignant melanoma.
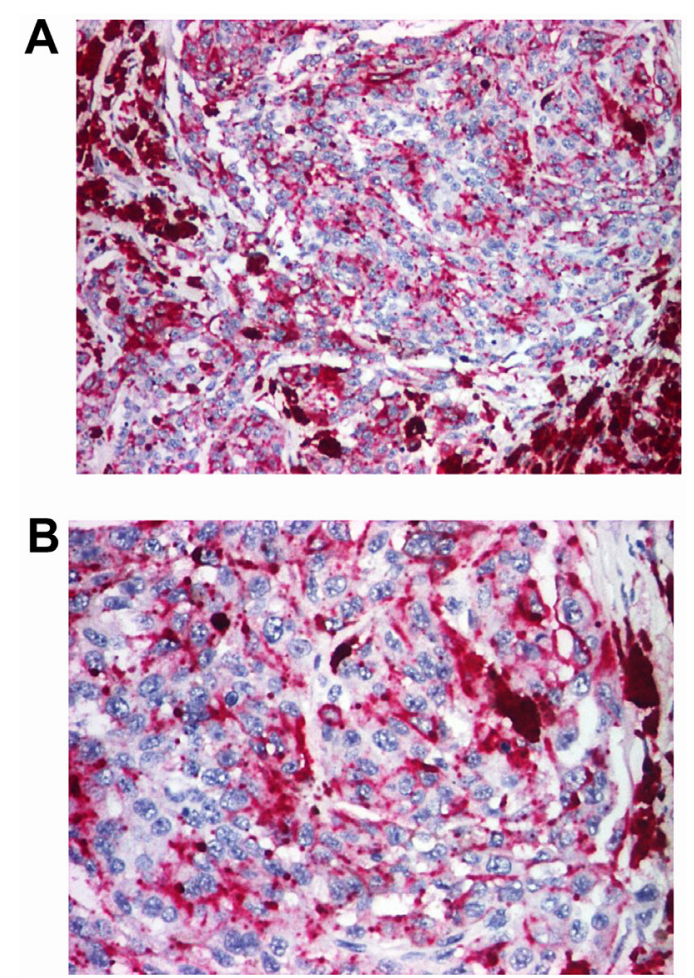

Figure 15. (A) Light microscopy of a paraffin-embedded satellite cutaneous metastasis, positive immunostaining for CD117; x100 magnification. (B) Light microscopy of a paraffin-embedded satellite cutaneous metastasis, positive immunostaining for CD117; x200 magnification.

between $10-50 \%$ of stained cells, and 2 cases showing over $50 \%$ of marked cells. It should be noted that 2 of the cases were positive for CD117 only in the epidermal component, the dermal component being negative. These two cases showed +3 immunostaining. As a result, the CD117 marker in ALM in the epidermal component was similar to SSM, and in the dermal component, it was similar to NM (Tables II and III).

Four cases of amelanotic MMs were observed with one case each of the categories analyzed in terms of the percentage of stained cells. CD117 immunostaining intensity in positive cases was low to moderate, with score 1 and 2 , and positivity only at the invasion front was observed in one case (Tables II and III). 
Table IV. Distribution of cases with $<10 \%$ and $\geq 10 \%$ of cells stained for CD117 by lesion type.

\begin{tabular}{lccc}
\hline & \multicolumn{3}{c}{$\begin{array}{c}\text { IHC of CD117 } \\
(\% \text { positive cells })\end{array}$} \\
\cline { 2 - 4 } Lesion type (55 cases) & $<10 \%$ & $\geq 10 \%$ & P-value \\
\hline Nevi (10 cases) & 80 & 20 & $0.01(\mathrm{~S})$ \\
Melanomas (35 cases) & 34.28 & 65.72 & - \\
Metastases (10 cases) & 50 & 50 & $0.366(\mathrm{NS})$ \\
\hline
\end{tabular}

IHC, immunohistochemistry; S, significant; NS, not significant.

Table V. Distribution of cases with $<10 \%$ and $\geq 10 \%$ of cells stained for CD117 depending on the intensity of the immunostaining.

\begin{tabular}{ccccc}
\hline & & \multicolumn{3}{c}{$\begin{array}{c}\text { IHC of CD117 } \\
(\% \text { positive cells })\end{array}$} \\
\cline { 3 - 5 } Intensity & No. of cases & $<10 \%$ & $\geq 10 \%$ & P-value \\
\hline $0 /+1$ & 29 & 68.96 & 31.04 & $0.000217(\mathrm{~S})$ \\
$+2 /+3$ & 26 & 19.23 & 80.77 & \\
\hline
\end{tabular}

IHC, immunohistochemistry; S, significant.

It should also be noted that, in primary MMs with in situ areas, these areas were strongly positive (intensity 3) to CD117; diffuse positivity was observed in almost all tumor cells.

Metastatic MMs (metastases) were considered negative to CD117 in $30 \%$ of cases, positive in $10 \%$ of tumor cells in $20 \%$ of cases, between $10-50 \%$ of positive tumor cells in $40 \%$ of cases and more than $50 \%$ of tumor cells in $10 \%$ of cases (Figs. 13-15). The immunomarker intensity in the metastases analyzed was mild and moderate, with no intensive positive metastases detected at CD117 (Tables II and III).

Analyzing the CD117 immunomarker in MM and nevi cases (simple nevi and dysplastic nevi), we found statistically significant differences $(\mathrm{P}=0.01)$ in the percentage of positive cells between the two categories; nevi were negative/stained in under $10 \%$ of cells compared to MM, which generally expressed CD117 in over 10\% of tumor cells. Thus, CD117 expression in MM was significantly increased compared to simple or dysplastic nevi (Table IV). Comparative analysis between MM and the metastases did not reveal significant differences $(\mathrm{P}=0.366)$, suggesting that MM metastases behave similarly to their primary tumors in terms of CD117 expression (Table IV).

By comparing all the cases included in the study, from the point of view of CD117 immunostaining, it was found that poor/absent immunostaining was significantly more common in cases expressing CD117 in a reduced cell number, under $10 \%$ of cells, compared to moderate/strong immunostaining that was characteristic of cases with $<10 \%$ of positive cells $(\mathrm{P}=0.000217)($ Table V).

\section{Discussion}

The expression of c-Kit has been detected in a variety of different tumor entities, such as gastrointestinal stromal tumors (GISTs), malignant melanoma (MM), breast and lung cancer, colon carcinoma, ovarian, hepatocellular, sarcoma and mastocytosis (16-20).

Regarding CD117 immunoexpression in MM, Gibson and Cooper showed that CD117 tends to immunostain strongly the in situ component of MM, with loss of coloration in deep dermal components and in NM (21).

This aspect was clearly observed in this study. Thus, in all LMM cases, areas of lentigo malignant (in situ lesions) were intensely and diffusely positive to CD117. In addition, all other primary MM types (SSM, ALM, amelanotic) associating MM domains in situ, were strongly positive (+3 intensity) for CD117, the positivity being diffused in nearly all tumor cells of the in situ component.

Furthermore, a decrease in the percentage of marked cells and the intensity of the immune marker in the deep dermal component was noted when compared to the dermo-epidermal junction in most of the analyzed MM types. NM cases lost color to CD177, being negative or positive in just under $10 \%$ of cells, in most cases (70\% of cases). A particular aspect of NM was the presence of the immunomarker CD117 only at the invasion front (in under $20 \%$ of the tumor cells); this pattern of the marker was probably correlated with the aggressive infiltrative progression of this type of MM.

Moreover, the present study showed that all cases of dysplastic nevi (100\% of the positive cases) were scored for CD117 in the dysplasia areas, while the simple nevi were always negative (100\% of the negative cases) to c-Kit.

Consequently, these results suggest that CD117 is involved in the MM tumorigenesis process, being heavily expressed in its initial stages (dysplasia, in situ lesion), after which the expression of CD117 decreases as the tumor progresses during the growth phase vertical. This involvement of c-Kit in the tumor transformation process was also supported by the significant differences observed between CD117 expression in MM compared to nevi $(\mathrm{P}=0.01)$.

It was also noted that the metastases expressed CD117 comparable to their primary tumors, with no statistically significant differences in the percentage of c-Kit-positive cells in primary and metastatic MM $(\mathrm{P}=0.366)$. Thus, although the intensity of the immunostaining in the metastases analyzed was mild and moderate, with no intensive positive metastases detected at CD117, MM metastases tended to retain c-Kit expression. Consequently, the similar expression of CD117 in primary and metastatic MM may suggest that loss of c-Kit expression by itself does not have a direct role in the metastatic process in MM, and other mechanisms are probably involved in this process (22).

This latter aspect was also demonstrated by other clinical studies on MM cell lines, showing that loss of c-Kit overexpression in MM cell lines is rather due to alteration in the expression of transcription factors, such as activating enhancer binding protein 2 (AP-2), which results in reduced expression of c-Kit (23).

CD117, a growth factor for melanocyte migration and proliferation, demonstrated in a previous study differentiated 
immunostaining in various benign and malignant melanocytic lesions, and the metastatic MM staining was lower than the primary MM dermal staining (24).

By comparing all the cases included in the study, from the point of view of CD117 immunoassay, it was found that weak/absent immunostaining is significantly more frequent in cases expressing CD117 in a reduced cell number, under $10 \%$ of cells, compared to moderate/strong immunostaining, which is characteristic of cases with over $10 \%$ of positive cells $(\mathrm{P}=0.000217)$. Similar results have been reported by other authors (23), suggesting that in MM, when CD117 is overexpressed, this overexpression is intense and diffuse, and can be a good screening method for selecting patients who could benefit from personalized therapy.

KIT changes in malignant tumors are of particular interest as KIT is one of the therapeutic targets of tyrosine kinase inhibitors (eg imatinib mesylate, sunitinib, nilotinib and dasatinib). Imatinib mesylate is a selective inhibitor of certain tyrosine kinases, including Abelson murine viral oncogene homolog $(\mathrm{ABL})$, breakpoint cluster region-Abelson (BCRABL), Abelson-related genes (ARG), KIT and factor receptors platelet-derived growth factor (PDGFR) (25).

Imatinib was initially found to be effective in the treatment of chronic myeloid leukaemia, where it addresses the BCR-ABL fusion protein and GIST treatment, where the tyrosine kinase c-Kit is directed $(26,27)$. Also, other KIT-positive tumors can benefit from kinase inhibitor therapy. It has been observed that the response rate can be particularly high in KIT-expressing tumors and include KIT activating mutations (28).

Similar findings in primary and metastatic MM (29-31), and studies that explored in vitro the sensitivity of malignant melanocytic cells to this drug, led to the assertion that imatinib mesylate is only effective in the context of KIT mutations $(32,33)$. KIT mutations have so far been found particularly in mucosal ALM or MM, which do not have UV exposure as a risk factor (34). MM inhibitors of KIT, imatinib and sunitinib and, more recently, nilotinib and dasatinib, have been included in MM treatment but were found to be less effective than in GIST $(35,36)$. Favorable results were shown for patients with metastatic MM, especially metastatic ocular MM $(37,38)$; the reports showed complete remission, lasting up to 1 year $(39,40)$.

MM with oncogenic mutations in KIT have been reported in several studies that focused on the role of KIT in melanocyte transformation $(19,34,41)$. Some cases of rare metastatic MM having KIT L576P activating mutation and strong and diffuse KIT expression (42) suggest that MM progression involves KIT activation and not loss of activity. It has been taken into consideration the use of tyrosine kinase inhibitors in these cases, which showed significant results in some studies $(43,44)$.

In a study of Medinger et al, a large series of solid tumors was immunohistochemically analyzed for c-Kit expression. The rate of c-Kit expression in solid tumors was low compared to GIST. However, relatively high c-Kit expression in sarcomas, $\mathrm{MM}$, renal cell carcinoma, seminoma, and neuroendocrine carcinoma is interesting and deserves further research (45).

Furthermore, we should be aware that the level of growth factor receptor expression does not always predict kinase inhibitor activity in the complex context of intracellular signaling pathways. Screening tumor samples for expression of growth factor-specific receptors is, however, very relevant as it provides valuable information on tumor characteristics, helping us better understand complex interactions of signal transduction pathways and guiding us in the development of more specific therapies (45).

CD117 immunoexpression in MM, significantly different from nevi $(\mathrm{P}=0.001)$, and the increased percentage of immune-positive MM (65.71\%) suggest that tyrosine kinase inhibitors may be useful in the treatment of cutaneous MM. Similar results have been reported by Alessandrini et al in a recent study in patients with conjunctival MM (46).

The role of KIT signaling in melanocyte biology has been extensively studied. It has been shown that the interaction of the stem cell factor with the KIT receptor is important for the survival, proliferation, differentiation and migration of melanocytes (47).

However, regulation of the KIT pathway is complex and depends on many other cellular factors (48). While KIT activating mutations are known to be associated with a variety of malignant human tumors, such as GIST, seminomas and mastocytosis/mastocytosis leukaemia (49), the introduction of a KIT activating mutation into an immortalized murine melanocytic cell line has been reported to have a more motogenic effect than a mitogenic one. Therefore, it was speculated that in order to obtain proliferative advantage and escape epidermal barriers, MM cells should lose KIT expression (50-52).

This hypothesis was supported by previous observations and those of a present study, in which KIT expression in MM is strong in in situ lesions and the junctional component of invasive lesions, but is lost once MM becomes invasive and metastatic $(23,53)$.

Recent information on the functional importance of multiple mutant genes (BRAF, N-RAS, KIT and PTEN) in MM has fundamentally changed the diagnostic and therapeutic approach. However, it is not surprising that, in a large number of MM cases, such single mutations do not clearly delineate the biological behavior of the tumor at the time of diagnosing a primary MM. In fact, it seems to be a multitude of biologically distinct MM entities (54).

Thus, this direct approach is likely to be insufficient given that in many MM, unknown oncogenes and/or tumor suppressors can control the fate of tumor cells (55). Most likely, MM approaches, using the 21st-century technology of the genetic profile, will yield interesting results (56).

However, there are some limitations of our study. We cannot provide an explanation for the different immunoexpression of CD117 in different types of melanoma, although some forms have similar expression levels of CD117 to melanoma metastasis, which is intriguing and requires further research.

CD117 (c-Kit) is massively involved in the process of tumorigenesis of cutaneous malignancies, being immunohistochemically undetectable in benign neural lesions, but densely expressed in dysplastic lesions (dysplastic nevi) and in situ melanoma areas.

In invasive cutaneous MM, CD117 expression tends to decrease as neoplasia progresses and procedes into the tumorigenic, vertical growth phase, being lower in the profound dermal component of tumors and in nodular melanomas.

To eliminate the epidermal barriers and gain a proliferative advantage to allow the transition to the vertical growth phase, it seems that MM should lose the expression of $\mathrm{c}-\mathrm{Kit}$. 
Malignant melanoma cutaneous metastases express CD117 at a level comparable to their primary tumors, suggesting that other mechanisms interfere directly with the metastasis process and not loss of c-Kit expression by itself.

CD117 overexpression in cutaneous melanocytic lesions ( $\geq 10 \%$ of tumor cells) correlates significantly with increased immunostaining intensity $(+2 /+3)$, suggesting that the immunohistochemical evaluation of CD117 may be a good method for screening patients, who could benefit from a personalized therapy with tyrosine kinase inhibitors.

\section{Acknowledgements}

Not applicable.

\section{Funding}

No funding was received.

\section{Availability of data and materials}

The datasets used and/or analysed during the current study are available from the corresponding author on reasonable request.

\section{Authors' contributions}

AR, CB, MAM and DEB contributed to the study design, participated in the entire review process and prepared the manuscript. IT, LEB, FDP, GS and DCB contributed to collecting the relevant literature, data analysis and critical interpretation. GS and DCB conceived the review and modified the manuscript. All authors read and approved the final version of the manuscript.

\section{Ethics approval and consent to participate}

The study was approved by the Universitary and Scientific Deontology and Ethics Committee of the University of Medicine and Pharmacy of Craiova (no. 78 from 27.03.2015), and informed consent was obtained from each patient. We complied, throughout the research, with the ethical standards of the Declaration of Helsinki, along with the university codes of Good Research Practice and Medical Ethics.

\section{Patient consent for publication}

The patients provided written informed consent for the publication of any associated data and accompanying images.

\section{Competing interests}

The authors declare that they have no competing interests.

\section{References}

1. Besmer P, Murphy JE, George PC, Qiu FH, Bergold PJ Lederman L, Snyder HW Jr, Brodeur D, Zuckerman EE and Hardy WD: A new acute transforming feline retrovirus and relationship of its oncogene v-kit with the protein kinase gene family. Nature 320: 415-421, 1986.
2. Yarden Y, Kuang WJ, Yang-Feng T, Coussens L, Munemitsu S, Dull TJ, Chen E, Schlessinger J, Francke U and Ullrich A: Human proto-oncogene c-kit: A new cell surface receptor tyrosine kinase for an unidentified ligand. EMBO J 6: 3341-3351, 1987.

3. Ashman LK: The biology of stem cell factor and its receptor C-kit. Int J Biochem Cell Biol 31: 1037-1051, 1999.

4. Ronnstrand L: Signal transduction via the stem cell factor/c-Kit. Cell Mol Life Sci 61: 2535-2548, 2004.

5. Arber DA, Tamayo R and Weiss LM: Paraffin section detection of the c-kit gene product (CD117) in human tissues: Value in the diagnosis of mast cell disorders. Hum Pathol 29: 498-504, 1998.

6. Maranduca MA, Branisteanu D, Serban DN, Branisteanu DC Stoleriu G, Manolache N and Serban IL: Synthesis and physiological implications of melanic pigments. Oncol Lett 17: 4183-4187, 2019.

7. Blendea A, Georgescu CV, Tolea I, Brănişteanu DE and Costache A: An unusual cutaneous malignant melanoma arised de novo: A case report. Rom J Morphol Embryol 56: 1217-1221, 2015.

8. Schatton T, Murphy GF, Frank NY, Yamaura K, Waaga-Gasser AM, Gasser M, Zhan Q, Jordan S, Duncan LM, Weishaupt $\mathrm{C}$, et al: Identification of cells initiating human melanomas. Nature 451: 345-349, 2008.

9. Reginster MA, Pierard-Franchimont C, Piérard GE and Quatresooz P: Molecular dermatopathology in malignant melanoma. Dermatol Res Pract 2012: 684032, 2012.

10. Klein WM, Wu BP, Zhao S, Wu H, Klein-Szanto AJ and Tahan SR: Increased expression of stem cell markers in malignant melanoma. Mod Pathol 20: 102-107, 2007.

11. Schatton T and Frank MH: Cancer stem cells and human malignant melanoma. Pigment Cell Melanoma Res 21: 39-55, 2008.

12. Rappa G, Fodstad O and Lorico A: The stem cell-associated antigen CD133 (Prominin-1) is a molecular therapeutic target for metastatic melanoma. Stem Cells 26: 3008-3017, 2008.

13. Zurac S, Neagu M, Constantin C, Cioplea M, Nedelcu R, Bastian A, Popp C, Nichita L, Andrei R, Tebeica T, et al: Variations in the expression of TIMP1, TIMP2 and TIMP3 in cutaneous melanoma with regression and their possible function as prognostic predictors. Oncol Lett 11: 3354-3360, 2016.

14. Quatresooz P, Pierard GE and Pierard-Franchimont C; Mosan Study Group of Pigmented Tumors: Molecular pathways supporting the proliferation staging of malignant melanoma (Review). Int J Mol Med 24: 295-301, 2009.

15. Quatresooz P and Piérard GE: Malignant melanoma: From cell kinetics to micrometastases. Am J Clin Dermatol 12: 77-86, 2011.

16. Tsuura Y, Hiraki H, Watanabe K, Igarashi S, Shimamura K, Fukuda T, Suzuki T and Seito T: Preferential localization of c-kit product in tissue mast cells, basal cells of skin, epithelial cells of breast, small cell lung carcinoma and seminoma/dysgerminoma in human: Immunohistochemical study on formalin-fixed, paraffin-embedded tissues. Virchows Arch 424: 135-141, 1994.

17. Matsuda R, Takahashi T, Nakamura S, Sekido Y, Nishida K, Seto M, Seito T, Sugiura T, Ariyoshi Y, Takahashi T, et al: Expression of the c-kit protein in human solid tumors and in corresponding fetal and adult normal tissues. Am J Pathol 142: 339-346, 1993.

18. Hornick JL and Fletcher CD: Immunohistochemical staining for KIT (CD117) in soft tissue sarcomas is very limited in distribution. Am J Clin Pathol 117: 188-193, 2002.

19. Went PT, Dirnhofer S, Bundi M, Mirlacher M, Schraml P, Mangialaio S, Dimitrijevic S, Kononen J, Lugli A, Simon R and Sauter G: Prevalence of KIT expression in human tumors. J Clin Oncol 22: 4514-4522, 2004

20. Becker G, Schmitt-Graeff A, Ertelt V, Blum HE and Allgaier HP: CD117 (c-kit) expression in human hepatocellular carcinoma. Clin Oncol (R Coll Radiol) 19: 204-208, 2007.

21. Gibson PC and Cooper K: CD117 (KIT): A diverse protein with selective applications in surgical pathology. Adv Anat Pathol 9: 65-69, 2002.

22. Fekete GL, Cotoi OS and Fekete JE: Multiple nodular cutaneous metastases as the first clinical sign of signet ring cell gastric carcinoma: Case report. Acta Dermatovenerol Croat 20: 34-37, 2012.

23. Torres-Cabala CA, Wang WL, Trent J, Yang D, Chen S, Galbincea J, Kim KB, Woodman S, Davies M, Plaza JA, et al: Correlation between KIT expression and KIT mutation in melanoma: A study of 173 cases with emphasis on the acral-lentiginous/mucosal type. Mod Pathol 22: 1446-1456, 2009. 
24. Isabel Zhu Y and Fitzpatrick JE: Expression of c-kit (CD117) in Spitz nevus and malignant melanoma. J Cutan Pathol 33: 33-37, 2006.

25. Heinrich MC, Griffith DJ, Druker BJ, Wait CL, Ott KA and Zigler AJ: Inhibition of c-kit receptor tyrosine kinase activity by STI 571, a selective tyrosine kinase inhibitor. Blood 96: 925-932, 2000.

26. Hochhaus A, Druker B, Sawyers C, Guilhot F, Schiffer CA, Cortes J, Niederwieser DW, Gambacorti-Passerini C, Stone RM, Goldman J, et al: Favorable long-term follow-up results over 6 years for response, survival, and safety with imatinib mesylate therapy in chronic-phase chronic myeloid leukemia after failure of interferon-alpha treatment. Blood 111: 1039-1043, 2008.

27. Demetri GD, von Mehren M, Blanke CD, Van den Abbeele AD, Eisenberg B, Roberts PJ, Heinrich MC, Tuveson DA, Singer S, Janicek M, et al: Efficacy and safety of imatinib mesylate in advanced gastrointestinal stromal tumors. N Engl J Med 347: 472-480, 2002

28. Heinrich MC, Corless CL, Demetri GD, Blanke CD, von Mehren M, Joensuu H, McGreevey LS, Chen CJ, Van den Abbeele AD, Druker BJ, et al: Kinase mutations and imatinib response in patients with metastatic gastrointestinal stromal tumors. J Clin Oncol 21: 4342-4349, 2003.

29. Alexis JB, Martinez AE and Lutzky J: An immunohistochemical evaluation of c-kit (CD-117) expression in malignant melanoma, and results of imatinib mesylate (Gleevec) therapy in three patients. Melanoma Res 15: 283-285, 2005.

30. Wyman K, Atkins MB, Prieto V, Eton O, McDermott DF, Hubbard F, Byrnes C, Sanders K and Sosman JA: Multicenter Phase II trial of high-dose imatinib mesylate in metastatic melanoma: Significant toxicity with no clinical efficacy. Cancer 106: 2005-2011, 2006.

31. Ugurel S, Hildenbrand R, Zimpfer A, La Rosée P, Paschka P, Sucker A, Keikavoussi P, Becker JC, Rittgen W, Hochhaus A and Schadendorf D: Lack of clinical efficacy of imatinib in metastatic melanoma. Br J Cancer 92: 1398-1405, 2005.

32. Antonescu CR, Busam KJ, Francone TD, Wong GC, Guo T, Agaram NP, Besmer P, Jungbluth A, Gimbel M, Chen CT, et al: L576P KIT mutation in anal melanomas correlates with KIT protein expression and is sensitive to specific kinase inhibition. Int J Cancer 121: 257-264, 2007.

33. Jiang X, Zhou J, Yuen NK, Corless CL, Heinrich MC, Fletcher JA, Demetri GD, Widlund HR, Fisher DE and Hodi FS: Imatinib targeting of KIT-mutant oncoprotein in melanoma. Clin Cancer Res 14: 7726-7732, 2008.

34. Curtin JA, Busam K, Pinkel D and Bastian BC: Somatic activation of KIT in distinct subtypes of melanoma. J Clin Oncol 24: 4340-4346, 2006.

35. Guo J, Si L, Kong Y, Flaherty KT, Xu X, Zhu Y, Corless CL, Li L, Li H, Sheng X, et al: Phase II, open-label, single-arm trial of imatinib mesylate in patients with metastatic melanoma harboring c-kit mutation or amplification. J Clin Oncol 29: 2904-2909, 2011

36. Carvajal RD, Antonescu CR, Wolchok JD, Chapman PB, Roman RA, Teitcher J, Panageas KS, Busam KJ, Chmielowski B, Lutzky J, et al: KIT as a therapeutic target in metastatic melanoma. JAMA 305: 2327-2334, 2011

37. Guerriere-Kovach PM, Hunt EL, Patterson JW, Glembocki DJ, English JC III and Wick MR: Primary melanoma of the skin and cutaneous melanomatous metastases: Comparative histologic features and immunophenotypes. Am J Clin Pathol 122: 70-77, 2004.

38. Grange JD, Duquesne N, Roubeyrol F, Branisteanu D, Sandon K, Fleury J, Gerard JP, Chauvel P, Pinzaru G, Jean-Louis B and Bievelez B: Double irradiation for macroscopic radioresistance or recurrence of melanomas of the posterior uvea: Clinical, ballistic, therapeutic and prognostic aspects. Series of 19 cases among 462 patients. J Fr Ophtalmol 22: 1054-1063, 1999.

39. Kim KB, Eton O, Davis DW, Frazier ML, McConkey DJ, Diwan AH, Papadopoulos NE, Bedikian AY, Camacho LH, Ross MI, et al: Phase II trial of imatinib mesylate in patients with metastatic melanoma. Br J Cancer 99: 734-740, 2008.
40. Ancuceanu R, Dinu M, Neaga I, Laszlo FG and Boda D: Development of QSAR machine learning-based models to forecast the effect of substances on malignant melanoma cells. Oncol Lett 17: 4188-4196, 2019.

41. Willmore-Payne C, Layfield LJ and Holden JA: c-Kit mutation analysis for diagnosis of gastrointestinal stromal tumors in fine needle aspiration specimens. Cancer 105: 165-170, 2005.

42. Willmore-Payne C, Holden JA, Tripp S and Layfield LJ: Human malignant melanoma: Detection of BRAF- and c-kit-activating mutations by high-resolution amplicon melting analysis. Hum Pathol 36: 486-493, 2005.

43. Fiorentini G, Rossi S, Lanzanova G, Bernardeschi P, Dentico P and De Giorgi U: Potential use of imatinib mesylate in ocular melanoma and liposarcoma expressing immunohistochemical c-Kit (CD117). Ann Oncol 14: 805, 2003.

44. Lutzky J, Bauer J and Bastian BC: Dose-dependent, complete response to imatinib of a metastatic mucosal melanoma with a K642E KIT mutation. Pigment Cell Melanoma Res 21: 492-493, 2008.

45. Medinger M, Kleinschmidt M, Mross K, Wehmeyer B, Unger C, Schaefer HE, Weber R and Azemar M: c-Kit (CD117) expression in human tumors and its prognostic value: An immunohistochemical analysis. Pathol Oncol Res 16: 295-301, 2010.

46. Alessandrini L, Parrozzani R, Bertorelle R, Valentini E, Candiotto C, Giacomelli L, Midena E and Blandamura S: C-Kit SCF receptor (CD117) expression and KIT gene mutation in conjunctival pigmented lesions. Acta Ophthalmol 91: e641-e645, 2013.

47. Grichnik JM, Burch JA, Burchette J and Shea CR: The SCF/KIT pathway plays a critical role in the control of normal human melanocyte homeostasis. J Invest Dermatol 111: 233-238, 1998.

48. Grichnik JM: Kit and melanocyte migration. J Invest Dermatol 126: 945-947, 2006.

49. Holden JA, Willmore-Payne C and Layfield LJ: Tyrosine kinase activating mutations in human malignancies: Implications for diagnostic pathology. Exp Mol Pathol 85: 68-75, 2008.

50. Alexeev V and Yoon K: Distinctive role of the cKit receptor tyrosine kinase signaling in mammalian melanocytes. J Invest Dermatol 126: 1102-1110, 2006.

51. Ciobotaru OR, Lupu MN, Rebegea L, Ciobotaru OC, Duca OM, Tatu AL, Voinescu CD, Stoleriu G, Earar K and Miulescu M: Dexamethasone-chemical structure and mechanisms of action in prophylaxis of postoperative side effects. Rev Chim (Bucharest) 70: 843-847, 2019.

52. Caruntu C, Boda D, Constantin C, Caruntu A and Neagu M: Catecholamines increase in vitro proliferation of murine B16F10 melanoma cells. Acta Endocrinol 10: 545-558, 2014.

53. Buga AM, Docea AO, Albu C, Malin RD, Branisteanu DE, Ianosi G, Ianosi SL, Iordache A and Calina D: Molecular and cellular stratagem of brain metastases associated with melanoma. Oncol Lett 17: 4170-4175, 2019.

54. Avram S, Coricovac DE, Pavel IZ, Pinzaru J, Ghiulai R, Baderca F, Soica C, Muntean D, Branisteanu DE, Spandidos DA, et al: Standardization of A375 human melanoma models on chicken embryo chorioallantoic membrane and Balb/c nude mice. Oncol Rep 38: 89-99, 2017.

55. Kaplan FM, Mastrangelo MJ and Aplin AE: The wrath of RAFs: Rogue behavior of B-RAF kinase inhibitors. J Invest Dermatol 130: 2669-2671, 2010.

56. Wagle N, Emery C, Berger MF, Davis MJ, Sawyer A, Pochanard P, Kehoe SM, Johannessen CM, Macconaill LE, Hahn WC, et al: Dissecting therapeutic resistance to RAF inhibition in melanoma by tumor genomic profiling. J Clin Oncol 29: 3085-3096, 2011.

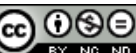

This work is licensed under a Creative Common Attribution-NonCommercial-NoDerivatives 4.0 International (CC BY-NC-ND 4.0) License. 